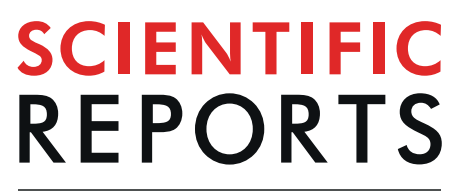

\title{
OPEN The TreaT-Assay: A Novel Urine- Derived Donor Kidney Cell-Based Assay for Prediction of Kidney Transplantation Outcome
}

\author{
Constantin J.Thieme ${ }^{1,2}$, Benjamin J. D. Weist ${ }^{1}$, Annemarie Mueskes ${ }^{1}$, Toralf Roch ${ }^{1,3}$, \\ Ulrik Stervbo $\mathbb{D}^{3}$, Kamil Rosiewicz ${ }^{1}$, Patrizia Wehler ${ }^{1,3}$, Maik Stein ${ }^{1,4}$, Peter Nickel ${ }^{5}$, \\ Andreas Kurtz ${ }^{1}$, Nils Lachmann ${ }^{6}$, Mira Choi ${ }^{5}$, Michael Schmueck-Henneresse ${ }^{1,7}$, \\ Timm H. Westhoff ${ }^{3}$, Petra Reinke ${ }^{1,4}$ \& Nina Babel ${ }^{1,3,7^{*}}$
}

Donor-reactive immunity plays a major role in rejection after kidney transplantation, but analysis of donor-reactive T-cells is not applied routinely. However, it has been shown that this could help to identify patients at risk of acute rejection. A major obstacle is the limited quantity or quality of the required allogenic stimulator cells, including a limited availability of donor-splenocytes or an insufficient HLA-matching with HLA-bank cells. To overcome these limitations, we developed a novel assay, termed the TreaT (Transplant reactive T-cells)-assay. We cultivated renal tubular epithelial cells from the urine of kidney transplant patients and used them as stimulators for donor-reactive T-cells, which we analyzed by flow cytometry. We could demonstrate that using the TreaT-assay the quantification and characterization of alloreactive T-cells is superior to other stimulators. In a pilot study, the number of pre-transplant alloreactive T-cells negatively correlated with the post-transplant eGFR. Frequencies of pre-transplant $\mathrm{CD} 161^{+}$alloreactive $\mathrm{CD4}^{+}$-cells and granzyme $\mathrm{B}$ producing alloreactive $\mathrm{CD} 8^{+}$ T-cells were substantially higher in patients with early acute rejection compared to patients without complications. In conclusion, we established a novel assay for the assessment of donor-reactive memory T-cells based on kidney cells with the potential to predict early acute rejection and posttransplant eGFR.

Kidney transplantation is the standard therapy for end-stage renal diseases. Acute (AR) or chronic rejection are among the biggest challenges in transplantation medicine, and donor reactive immunity is an important factor that counters allograft acceptance ${ }^{1}$. Immunosuppressive medication is given to control or prevent immune reactions; however, this medication has serious side effects. Many previous studies report heterogeneous risk profiles with respect to post-transplant complications such as AR or infections, suggesting introduction of personalized immunosuppressive therapy regimen ${ }^{2-4}$. For such individual therapy biomarkers that allow the discrimination between patients with different risk profiles are required ${ }^{2,4-6}$. The presence of donor-reactive $\mathrm{T}$ cells pre- and

\footnotetext{
${ }^{1}$ Berlin Institute of Health Center for Regenerative Therapies (BCRT), Charité - Universitätsmedizin Berlin, corporate member of Freie Universität Berlin, Humboldt-Universität zu Berlin, and Berlin Institute of Health, Berlin, Germany. ${ }^{2}$ Berlin-Brandenburg School for Regenerative Therapies (BSRT), Charité - Universitätsmedizin Berlin, corporate member of Freie Universität Berlin, Humboldt-Universität zu Berlin, and Berlin Institute of Health, Berlin, Germany. ${ }^{3}$ Center for Translational Medicine, Medical Department I, Marien Hospital Herne, University Hospital of the RuhrUniversity Bochum, Herne, Germany. ${ }^{4}$ Berlin Center for Advanced Therapies (BeCAT), Charité - Universitätsmedizin Berlin, corporate member of Freie Universität Berlin, Humboldt-Universität zu Berlin, and Berlin Institute of Health, Berlin, Germany. ${ }^{5}$ Department of Nephrology and Intensive Internal Care, Charité - Universitätsmedizin Berlin, corporate member of Freie Universität Berlin, Humboldt-Universität zu Berlin, and Berlin Institute of Health, Berlin, Germany. ${ }^{6}$ Zentrum für Transfusionsmedizin und Zelltherapie, Charité - Universitätsmedizin Berlin, corporate member of Freie Universität Berlin, Humboldt-Universität zu Berlin, and Berlin Institute of Health, Berlin, Germany. Institute for Medical Immunology, Charité - Universitätsmedizin Berlin, corporate member of Freie Universität Berlin, HumboldtUniversität zu Berlin, and Berlin Institute of Health, Berlin, Germany. *email: nina.babel@charite.de
} 


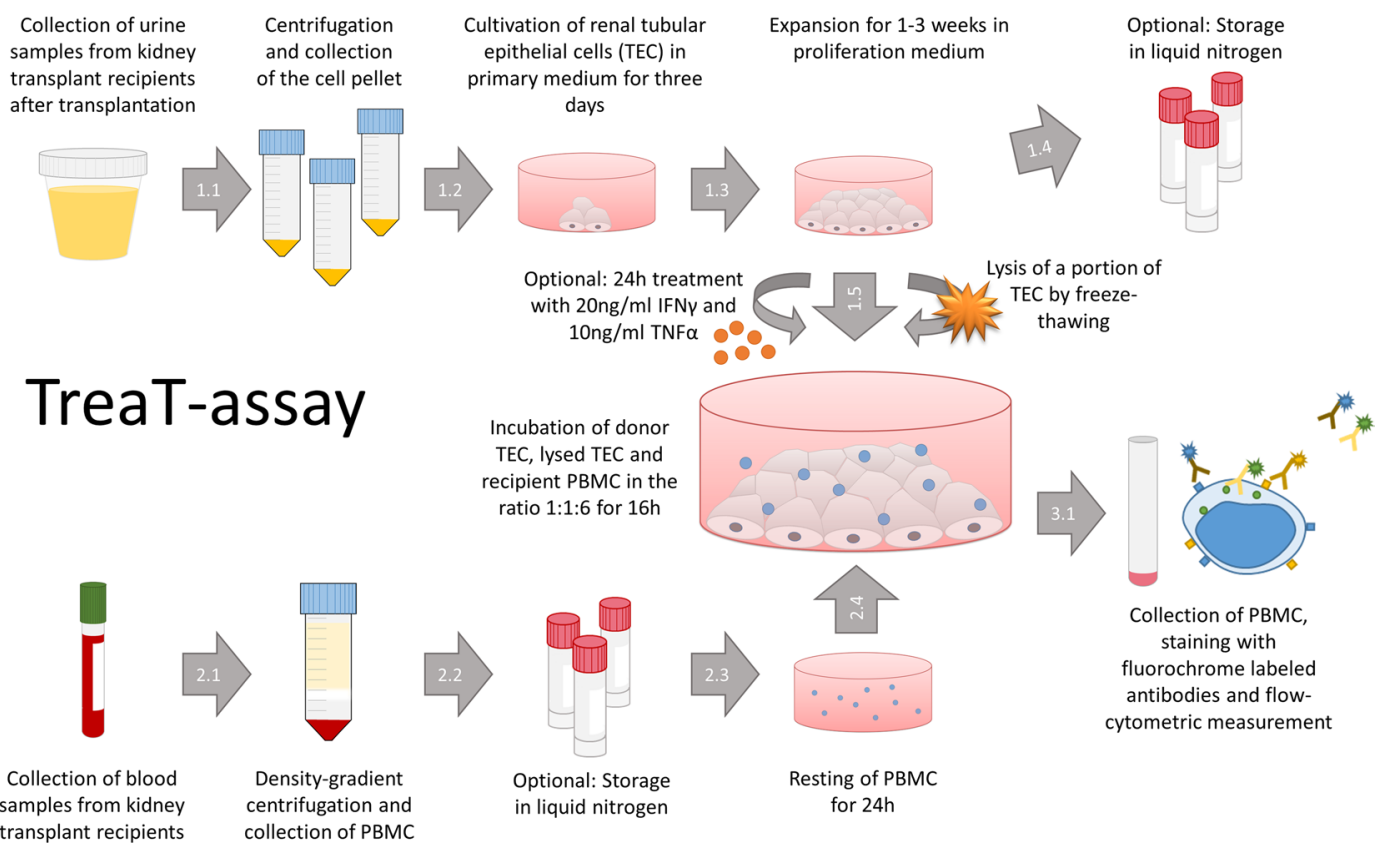

Figure 1. Methodological overview of the TreaT-assay. For a detailed description please consult the materials and methods section of the main text.

post-kidney-transplantation has been demonstrated to be associated with AR and reduced allograft survival ${ }^{1,7,8}$. Therefore, $\mathrm{T}$ cell allosensitization assays have been developed and successfully tested as predictors of the transplant outcome $e^{7,9-12}$. In these assays, the recipient's peripheral blood cells are stimulated by alloantigen sources presenting foreign human leukocyte antigen (HLA) molecules. Currently, two sources of stimulator cells are used. One source are donor splenocytes collected during removal of the donor kidney ${ }^{12,13}$. However, the availability of splenocytes is limited and only feasible from deceased donors. The second source of allogenic cells is a cell bank representing the most common HLA-types ${ }^{10,13}$. Unfortunately, these cells often lack the adequate quality as the matching between donor and recipient HLA-types is frequently insufficient. Furthermore, since both sources are not allograft-derived, the peptides they present do not exactly resemble the tissue specific peptides presented by renal tubular epithelial cell (TEC), the main target during $\mathrm{AR}^{14}$. Another limitation of the currently used methods is the lack of a broad phenotypic and functional characterization of the detected alloreactive cells ${ }^{3}$. These underscore the need for a specific and sensitive assay for the monitoring and in-depth characterization of allograft-reactive T cells. We therefore developed the Transplant reactive $\mathrm{T}$ cell (TreaT)-assay by means of donor-derived renal cells obtained from recipient's urine, a handy and renewable antigenic source for stimulation. Using multiparameter flow cytometry, we showed that our assay has the potential to predict the graft function post-transplantation and early episodes of AR and could thus serve as an important tool for guiding precision immunosuppressive regimens in kidney transplant patients. Furthermore, the characterization of alloreactive $T$ cells has the potential to reveal new molecules involved in the process of AR.

\section{Materials and Methods}

An overview of the TreaT-assay setup can be found in Fig. 1.

Patients. Four healthy volunteers as well as in total twenty-two patients transplanted in the Charité Universitätsmedizin Berlin were recruited and analyzed in a cross-sectional study for the assay establishment at different time-points pre- and post-transplantation. No organs were procured from prisoners. The number of patients and samples analysed in the study differed in dependence from the aim addressed in the study. Thus, 22 patients were recruited for the cultivation procedure of TEC. For analysis of HLA expression on TEC, samples of 18 patients were used. For the assay establishment, samples of 13 patients were collected. The prediction of eGFR were performed using the samples of 14 patients, and 12 patients were followed up clinically for the prediction of acute rejection. For the comparison of stimulatory capacity between splenocytes and TEC, samples of 4 patients were collected (Supplementary Table S1). All patients gave written informed consent and the study was approved by the ethics commission of the Charité - Universitätsmedizin Berlin, Germany in accordance with the declaration of Helsinki.

Collection of peripheral blood mononuclear cells (PBMCs). Blood was collected from each kidney transplant recipient recruited into the study at least once and up to four times in Vacutainers containing lithium heparin (Beckton Dickinson (BD), Franklin Lakes, US-NJ). The PBMCs were isolated by density gradient centrifugation Ficoll-Paque (Biochrom, Berlin, Germany). The cells were frozen in CryoPure tubes (Sarstedt, Nümbrecht, Germany) in Roswell Parm Memorial Institute-1640 medium (RPMI, Biochrom) with $60 \%$ fetal bovine serum (FBS, Biochrom) and $10 \%$ dimethylsulfoxid (DMSO; Sigma-Aldrich, Munich, Germany) at $-80^{\circ} \mathrm{C}$ 
in a freezing box (ThermoFisher, Waltham, US-MA) containing isopropylalcohole (Sigma-Aldrich) and stored in liquid nitrogen until further usage. Upon defrosting, the cells were left resting for 24 hours.

Cultivation of tubular epithelial cells. Up to $300 \mathrm{ml}$ of urine were collected in sterile flasks (Corning Falcon, Corning, US-NY) within the first week after kidney transplantation. To ensure the donor origin of urine cells, urine was collected from mono pigtail stents in patients with existing residual diuresis. The samples were then processed further according to a previously published protocol ${ }^{15}$. Briefly, the urine sediment was washed with phosphate buffered saline (PBS, ThermoFisher) and seeded in primary medium, containing Dulbecco's modified Eagle medium (DMEM, ThermoFisher) and Ham's F12 (Biochrom) in a $1 / 1$ ratio, 10\% FBS, renal epithelial growth medium (REGM) SingleQuot kit (Lonza Clonetics), $100 \mathrm{U} / \mathrm{ml}$ penicillin/streptomycin (P/S, Biochrom), $2.5 \mu \mathrm{g} / \mathrm{ml}$ amphotericin B (Biochrom), $100 \mu \mathrm{g} / \mathrm{ml}$ normocin (InvivoGene) and $10 \mu \mathrm{g} / \mathrm{ml}$ ciprofloxacin (Fresenius Kabi Austria). After three days, the medium was replaced by the proliferation medium, containing renal epithelial basal medium (REBM, Lonza, Basel, Swiss), REGM SingleQuot kit, 10\% FBS, 2.5 mM GlutaMAX (ThermoFisher), $1 \%$ non-essential amino acids (ThermoFisher) and $100 \mathrm{U} / \mathrm{ml} / 100 \mu \mathrm{g} / \mathrm{ml} \mathrm{P} / \mathrm{S}$. Mycoplasma contamination was monitored in random samples (MycoAlert, Lonza). The cells were cultivated until confluency, harvested using trypsin/EDTA-solution (Biochrom), and frozen as described above until further usage.

Induction of HLA expression. Frozen tubular epithelial cells (TEC) were thawed, seeded in two cell-culture flasks of $75 \mathrm{~cm}^{2}$ (Coning Falcon), and cultivated in proliferation medium until confluency. Then, the flasks were incubated with RPMI containing $10 \% \mathrm{FBS}$ and $100 \mathrm{U} / \mathrm{ml} \mathrm{P} / \mathrm{S}$ with or without supplementation of $20 \mathrm{ng} / \mathrm{ml}$ interferon $\gamma(\mathrm{IFN} \gamma)$ and $10 \mathrm{ng} / \mathrm{ml}$ tumor necrosis factor $\alpha(\mathrm{TNF} \alpha)$ (both Miltenyi Biotec, Bergisch-Gladbach, Germany) to enhance or induce surface HLA-ABC and -DR expression. After 24h, the TEC were harvested. A fraction of the cells was analysed by flow cytometry and the rest was used as stimulators in an alloantigen-assay.

Cell lysis. To mimic tissue damage and to facilitate presentation of alloantigens by antigen presenting cells, a fraction of TEC were lysed by centrifugation with $4500 \mathrm{~g}$, vortexing and repeated freeze-thawing at $-20^{\circ} \mathrm{C}$ in RPMI until further usage.

Preparation of donor splenocytes. Pieces of at least $6 \mathrm{~cm}$ of spleen from kidney-transplant donors were used for further preparation. Splenic connective tissue was removed with sterile forceps and scalpel (Feather, Osaka, Japan) and minced through a $100 \mu \mathrm{m}$ and a $40 \mu \mathrm{m}$ sterile cell strainer sieve (BD) with PBS. Mononuclear cells were isolated by Ficoll gradient and frozen as described above. Frozen splenocytes were thawed in RPMI containing 1\% DNAse (Roche Diagnostics, Rotkreuz, Swiss) $12 \mathrm{~h}$ prior to use in the alloantigen-assay. A fraction of the splenocytes was lysed as described above. To discriminate recipient's PBMC and donor splenocytes in flow cytometry, the remaining splenocytes were labelled with $5 \mu \mathrm{M}$ carboxyfluorescein succinimidyl ester (CFSE, Sigma) one hour before cultivation in the alloantigen-assay.

Alloantigen-assay. $\quad 0.25 \times 10^{6} \mathrm{TEC}$ treated with or without IFN $\gamma$ - and TNF $\alpha$ were seeded into 24 -well-plates (Corning Falcon). $1.5 \times 10^{6}$ recipient PBMCs and lysates of $0.25 \times 10^{6}$ TEC were added (ratio TEC:lysed TEC:PBMC = 1:1:6). For the experiments comparing autologous with allogenic stimulation, TEC isolated from two healthy volunteers were incubated with fresh, not cryopreserved PBMCs of the same or a different donor. PBMCs seeded into wells without TEC and lysed TEC served as the negative control. The positive control was treated with phorbol 12-myristate 13-acetate (PMA, Sarstedt) and ionomycin (Iono, ThermoFisher). All wells were incubated with $1 \mu \mathrm{g} / \mathrm{ml}$ brefeldin A (Sigma) and $1 \mu \mathrm{l} / \mathrm{ml}$ protein transport inhibitor containing monen$\sin (\mathrm{BD})$. Additional specimen with $0.25 \times 10^{6} \mathrm{CFSE}$ labelled kidney transplant donor-derived splenocytes and $0.25 \times 10^{6}$ lysed splenocytes as stimulators for $1.5 \times 10^{6}$ recipients' PBMCs were set. After 16 hours of incubation the PBMCs were harvested and stained for flow cytometry.

Flow cytometry staining of TEC and PBMCs. Cell surface of PBMCs and splenocytes was stained with anti-CD161 Brilliant Violet (BV) 510 (clone HP-3G10, Biolegend, San Diego, US-CA) and Live/ Dead Blue (ThermoFisher) to exclude dead cells. Intracellular staining of PBMCs was performed with FoxP3-Permeabilization Buffer (ThermoFisher) and with anti-CD3 Brilliant Ultraviolet 737 (clone UCHT1, BD), anti-CD4 BV650 (clone OKT4, Biolegend), anti-CD8 allophycocyanin (APC)/Cy7 (clone RPA-T8, Biolegend), anti-CD137 phycoerythrin (PE)/Cy5 (clone 4B4-1, BD), anti-CD154 peridinin-chlorophyll-protein (PerCP)/ Cy5.5 (clone 24-31, Biolegend) and anti-granzyme B Alexa Fluor 700 (clone GB11, BD).

Cell surface of TEC was stained with Live/Dead Blue, anti-CD13 APC (clone WM15, Biolegend), anti-CD90 PerCP/Cy5.5 (clone 5E10, Biolegend), anti-CD326 (EpCam) FITC (9C4, Biolegend), anti-HLA-ABC PE (clone 311506, Biolegend) and anti-HLA-DR APC/Cy7 (clone L243, Biolegend). Anti-cytokeratin BV421 (clone CAM5.2, BD) was administered for intracellular staining. Anti-HLA-ABC PE and anti-HLA-DR APC/Cy7 were also used for staining of splenocytes.

Patient samples were measured using LSRFortessa (BD) while healthy donors were measured using CytoFlex LX (Beckman Coulter, Brea, US-CA). Gating and analysis was performed with FlowJo version 10 (FlowJo LLC, Ashland, US-OR). Analyses of patient samples and healthy blood donors by two different flow cytometers were not critical, since the data of both populations were not directly compared to each other in the study.

Statistical analysis and graphical representation. Gating of flow cytometry data was performed with unstained, untreated, and adequate fluorescence minus one (FMO) controls according to standard flow cytometry guidelines ${ }^{16}$. HLA expression on TEC was analysed as median fluorescence intensity (MFI). CD137/CD154 $\mathrm{CD}^{+}$and $\mathrm{CD} 137^{+} \mathrm{CD}^{+} \mathrm{T}$ cells and their subsets were analysed as cells per $10^{6} \mathrm{CD} 4^{+}$and $\mathrm{CD} 8^{+} \mathrm{T}$ cells, respectively. Counts of less than two cells per gate were excluded. To account for specifically activated cells and their 

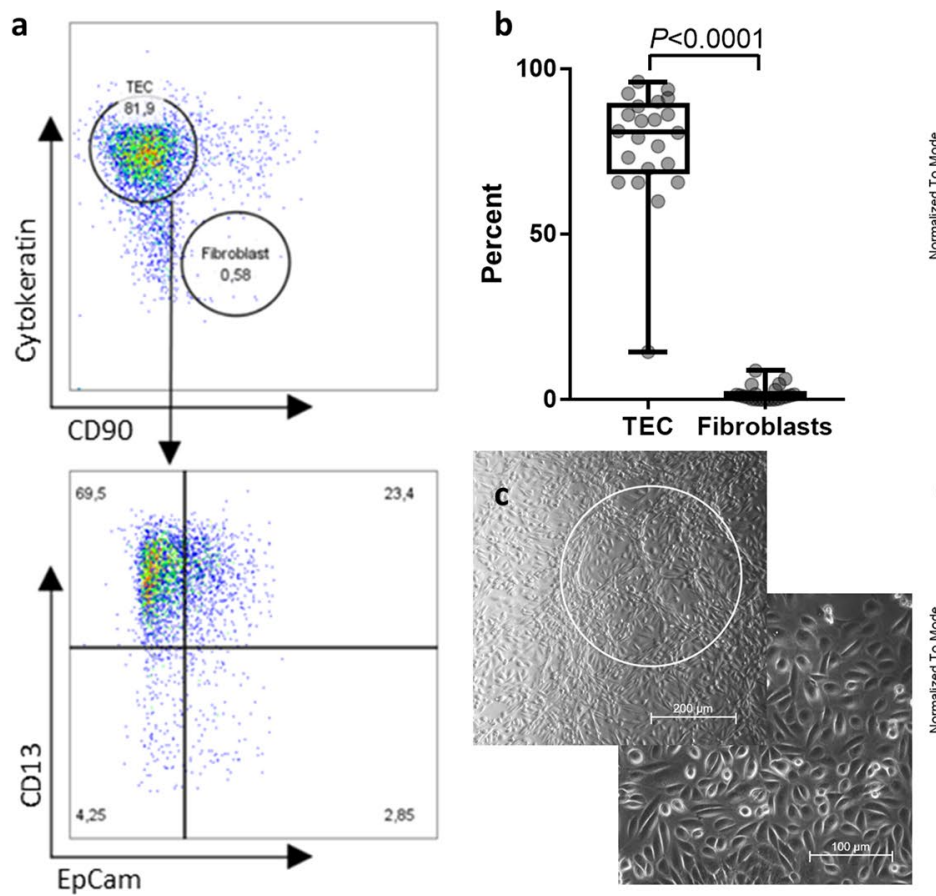
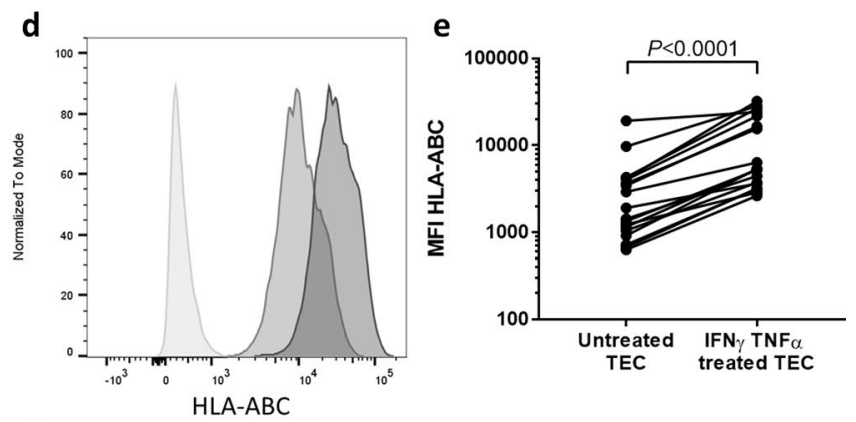

Unstainer
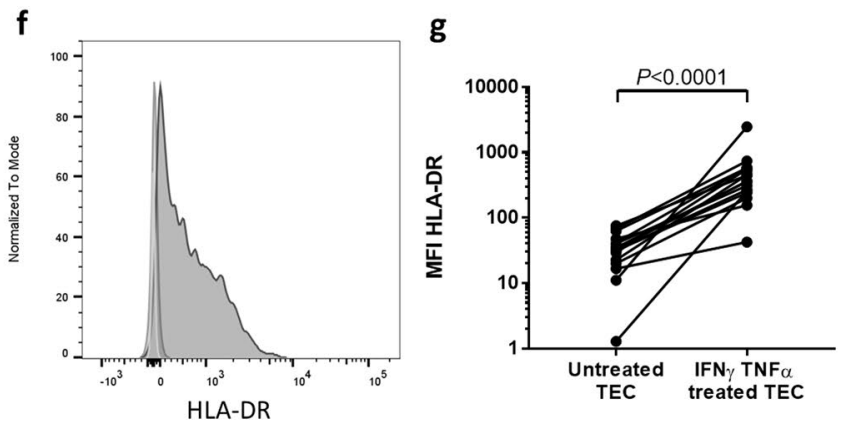

Figure 2. Urinary culture cells mainly consist of tubular epithelial cells (TEC) and present HLA-ABC and -DR-molecules upon IFN $\gamma$ and TNF $\alpha$ treatment. (a) Representative flow cytometric characterization of urinary culture cells. Urine was collected from kidney-transplant patients after transplantation and the cell pellet was seeded in culture media after centrifugation. The colonies were then expanded in proliferation media for 1-3 weeks. After harvesting, the cells were stained for epithelial cell marker cytokeratin, proximal and distal renal tubular cell markers CD13 and EpCam, and for fibroblast marker CD90. One representative example of 22 individual donors is demonstrated. (b) Quantification of TEC (cytokeratin ${ }^{+} \mathrm{CD}^{-} 0^{-}$) and Fibroblasts (cytokeratin $\left.{ }^{-} \mathrm{CD}^{+} 0^{+}\right)$among living urinary culture cells $(n=22)$. Cells were analysed after $3-6$ weeks in culture. Statistical comparison was done with Wilcoxon matched-pairs signed rank test for not normally distributed samples. (c) Representative phase-contrast microscopy of two samples of urinary cell cultures. The upper picture shows the characteristic dome formation of TEC (white circle). The cell morphology shown in the lower picture indicates epithelial cells. Magnification $20 \times($ left $)$ and $10 \times($ right $)$. A representative example for 22 individual donors is shown. $(\mathbf{d}-\mathbf{g})$ Expression levels indicated by median fluorescence intensity (MFI) of HLA-ABC (d,e) and HLA-DR $((\mathbf{f}, \mathbf{g})$ on urine-derived TEC with and without addition of $20 \mathrm{ng} / \mathrm{ml}$ IFN $\gamma$ and $10 \mathrm{ng} / \mathrm{ml} \mathrm{TNF} \alpha$ for $24 \mathrm{~h}(n=18)$. Harvested cells were analysed by flow cytometry. Histograms are representative for $\mathrm{n}=18$. Statistical analysis was done with Wilcoxon matched-pairs signed rank test for not normally distributed samples.

phenotype, the corresponding population in the negative control was subtracted, except for the experiments to show the specificity of the assay where the negative control is depicted for a better illustration of the background T cell activity. Statistical analysis was performed with Prism 7 (GraphPad Software, San Diego, US-CA). Gaussian distribution was assessed using D’Agostino \& Pearson normality test and Shapiro-Wilk normality test. Parametric or non-parametric statistical tests were used accordingly as indicated. In detail, comparison of HLA expression as well as the reactivity of recipient PBMC to donor UC and splenocytes was done with Wilcoxon matched-pairs signed rank test for not normally distributed samples. To test the ability of UC to stimulate alloantigen-reactive T cells, non-parametric statistics was done with Friedman-Test and Dunn's multiple comparison test. As sphericity was not assumed, the Greisser-Greenhouse correction was applied. Correlation of eGFR (calculated with CKD-EPI) and pre-transplant alloreactive T cells was calculated with Pearson's correlation coefficient.

\section{Results}

Generation of urine-derived tubular epithelial cells and induction of HLA-ABC and-DR expression. In total, four healthy individuals and twenty-two kidney-transplant patients were included in a cross-sectional study in order to establish our novel methodological approach. Cells were cultured from all twenty-two patients and two healthy individuals. Flow cytometric expression of cytokeratin, CD13, and epithelial cell adhesion molecule (EpCam), which define tubular epithelial cells (TEC) ${ }^{17,18}$, as well as CD90 as a marker for contaminating fibroblasts ${ }^{19}$ was analysed. We found that the vast majority of the cultivated cells consists of TEC (median $81 \%$, IQR 69-89\%), mainly proximal $\left(\mathrm{CD}^{+} 3^{+}\right)$and to a lesser extent distal (EpCam ${ }^{+}$) TEC (Fig. 2A,B). Microscopical evaluation confirmed the epithelial phenotype and the dome formation that is characteristic for TEC (Fig. 2C). We will therefore refer to the cells cultured from the urine as TEC in the following paragraphs.

To mimic the inflammatory environment during rejection and enhance HLA expression, the TEC were treated with IFN $\gamma$ and TNF $\alpha$ for $24 \mathrm{~h}^{20}$. The flow cytometric analysis of the HLA expression confirmed an 


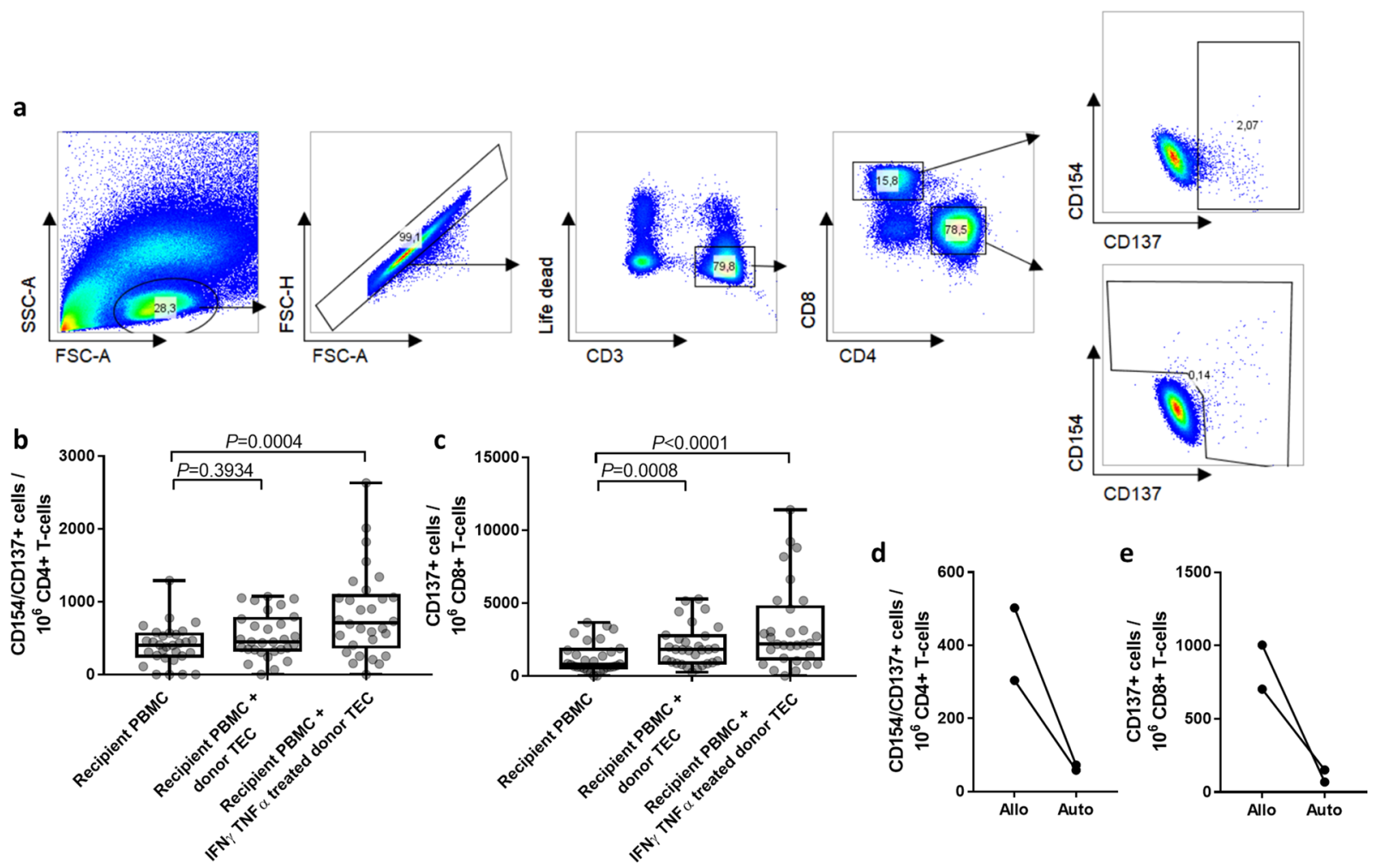

Figure 3. Alloreactive T cells can be monitored with urine-derived donor TEC. (a) Representative flow cytometry plots illustrating the gating strategy to identify single living alloreactive $\mathrm{CD} 3^{+} \mathrm{CD} 4^{+} \mathrm{CD} 154^{+}$/ $\mathrm{CD}_{137} 7^{+}$and $\mathrm{CD}^{+} \mathrm{CD} 137^{+}$lymphocytes. From left to right: Scatter plot of PBMCs distinguishing lymphocytes from debris and non-lymphocytes; doublet exclusion; discrimination of live $\mathrm{CD}^{+} \mathrm{T}$ cell from dead and non- $\mathrm{T}$ cells; discrimination of $\mathrm{CD}^{+}$and $\mathrm{CD}^{+} \mathrm{T}$ cells; identification of reactive $\mathrm{T}$ cells according to $\mathrm{CD} 137$ and CD154 expression. (b-c) Urine-derived donor TEC can elicit a donor-reactive activation of recipients' CD4 ${ }^{+}$ (b) and $\mathrm{CD}^{+}(\mathbf{c}) \mathrm{T}$ cells. PBMC of 13 recipients obtained at different time points $(n=30)$ were co-cultivated for $16 \mathrm{~h}$ with lysed and intact urine-derived donor TEC or with no further stimuli (negative control). The specific stimulation was further compared between donor TEC treated with $20 \mathrm{ng} / \mathrm{ml} \mathrm{IFN} \gamma$ and $10 \mathrm{ng} / \mathrm{ml}$ TNFo for $24 \mathrm{~h}$ or untreated TEC. Activation of T cells was assessed by flow cytometric determination of CD4 $4^{+} \mathrm{CD} 137^{+} /$ $\mathrm{CD}_{154^{+}}$and $\mathrm{CD} 8^{+} \mathrm{CD} 137^{+} \mathrm{T}$ cells as described in (a). Statistical comparison between the three experimental groups was performed with Friedman test and Dunn's multiple comparisons test. (d-e) Urine-derived TEC do not elicit an activation of autologous $\mathrm{CD}^{+}(\mathbf{d})$ and $\mathrm{CD}^{+}(\mathbf{e}) \mathrm{T}$ cells. TEC of two healthy donors were cultivated, treated with $20 \mathrm{ng} / \mathrm{ml} \mathrm{IFN} \gamma$ and $10 \mathrm{ng} / \mathrm{ml} \mathrm{TNF} \alpha$, partially lysed and incubated with autologous (auto) or randomly selected allogenic (allo) PBMCs ( $n=4$ PBMC donors). T cell activation was assessed as described above.

increase of HLA-ABC on TEC when compared to the untreated sample (Fig. 2D,E; $P<0.0001, n=20$ ). Similarly, HLA-DR on TEC significantly increased after TNF $\alpha$ and IFN $\gamma$ treatment (Fig. $2 \mathrm{~F}, \mathrm{G} ; P<0.0001, n=20$ ). Taken together, as it has been shown before for TEC derived directly from donor kidneys ${ }^{21}$, our data portray the ability of urine-derived TEC to act as atypical antigen-presenting cells.

Alloreactive T cells can be stimulated with urine-derived TEC. To examine whether we can induce a specific activation of alloantigen-reactive T cells, we analysed the activation marker profile of $\mathrm{T}$ cells following $16 \mathrm{~h}$ of co-cultivation of recipient PBMC with respective donor TEC. Lysed TEC were added to intact TEC to facilitate presentation by antigen presenting cells and to mimic ischemic cell death that can occur during transplantation. Recipient PBMC alone were used to define the T cell baseline activation. For the assay establishment, PBMCs from 13 patients were obtained, some of them at different time points, so 30 samples were analysed in total.

Activated CD4 ${ }^{+} \mathrm{T}$ cells were defined as activation marker CD154 and CD137 positive cells (Fig. 3A). Compared to the untreated controls we observed a significantly higher number of activated $\mathrm{CD} 4^{+} \mathrm{T}$ cells in cultures where the TEC have been stimulated with IFN $\gamma$ and TNF $\alpha$ (Fig. 3B; $P=0.0004, n=30$ ). Of note, untreated TEC did not induce specific activation of $\mathrm{CD}^{+} \mathrm{T}$ cells $(P=0.3934, n=30)$.

With regard to $\mathrm{CD} 8^{+} \mathrm{T}$ cells, we observed an even higher proportion of alloreactive cells compared to the $\mathrm{CD} 4^{+} \mathrm{T}$ cells. Cytokine-treated TEC induced a significantly higher number of CD $137^{+} \mathrm{CD} 8^{+} \mathrm{T}$ cells compared to the negative control (Fig. $3 \mathrm{C} ; P<0.0001, n=30$ ). In contrast to CD4 ${ }^{+} \mathrm{T}$ cells, they could also be activated by untreated TEC $(P=0.0008, n=30)$, although the magnitude of the response was lower. 
a
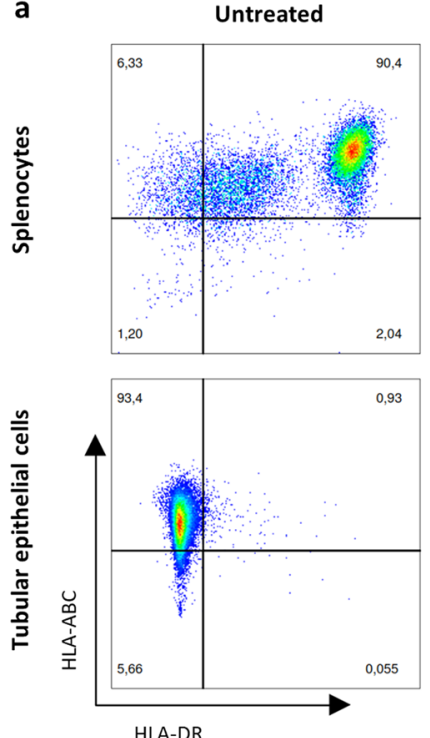

IFN $\gamma$ and TNF $\alpha$ treated
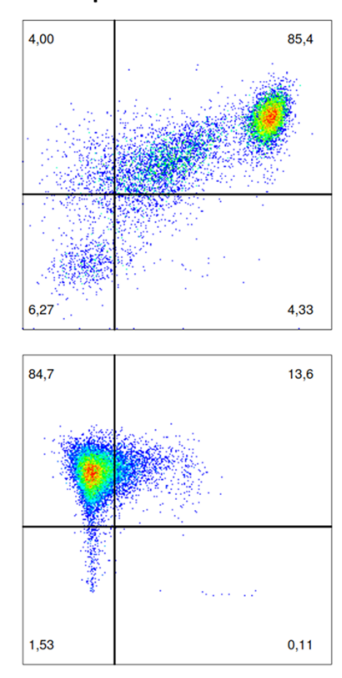

b

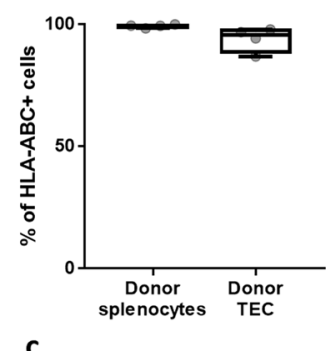

c

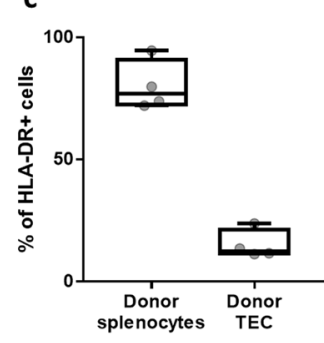

d
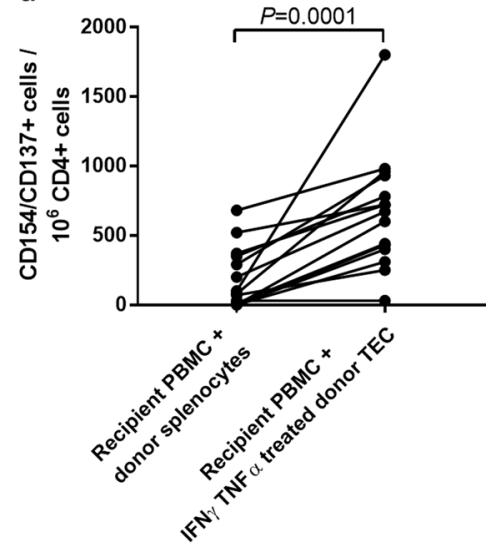

Figure 4. Assessment of alloreactive T cells using urine-derived donor TEC-stimulation shows higher sensitivity compared to donor splenocytes-stimulation. (a) Splenocytes express higher levels of HLA-DR than TEC. Representative plots demonstrating flow cytometric analysis of HLA-ABC and HLA-DR expression on untreated and $24 \mathrm{~h}$ IFN $\gamma$ and TNF $\alpha$ treated urine-derived TEC or splenocytes. Both cell types were derived from the same deceased donor. (b,c) Frequencies of HLA-ABC (b) and HLA-DR (c) expressing living splenocytes and treated living TEC determined by flow cytometry $(n=4)$. (d) TEC elicit a higher alloreactivity than splenocytes from the same donor. PBMCs of four kidney-allograft recipients of different time points $(n=15)$ were stimulated with IFN $\gamma$ and TNF $\alpha$ treated TEC and lysed TEC or splenocytes and lysed splenocytes, both derived from the kidney-transplant donor. Specific activation was assessed by flow cytometric measurements of the activation marker CD154 and CD137 expression on $\mathrm{CD} 4^{+} \mathrm{T}$ cells. Statistical analysis was done with Wilcoxon matched-pairs signed rank test.

To exclude that the observed reactivity reflects an unspecific reaction to cultivated and lysed TEC, we performed additional experiments with randomly selected healthy individuals $(n=4)$, where we used cytokine-treated TEC of two of these individuals as stimulators for either PBMCs of the same donor (auto) or of an allogenic donor (allo) (Fig. 3D,E). The healthy volunteers were randomly selected without specific HLA recruitment criteria as previously published ${ }^{22}$. While the frequencies of autologous activated $\mathrm{CD} 4^{+}$and $\mathrm{CD} 8^{+} \mathrm{T}$ cells were negligible, allo-specific $\mathrm{CD} 4^{+}$and $\mathrm{CD} 8^{+} \mathrm{T}$ cells were detectable (304-502.7 for $\mathrm{CD} 4^{+}$and $703.5-1004.2$ for $\mathrm{CD}^{+}$alloreactive $\mathrm{T}$ cells $/ 10^{6} \mathrm{~T}$ cells). Collectively, these data show that donor-reactive $\mathrm{T}$ cells can be detected using the assay based on urine-derived TEC of kidney transplant patients.

Donor-TEC demonstrate superior stimulatory capacity compared to donor-splenocytes. Usage of donor-splenocytes for monitoring alloreactive $\mathrm{T}$ cells is a well-established and elegant method, but only applicable for deceased donations. Urine-derived TEC offer the advantages of an unlimited availability of cells directly from the transplanted organ. We performed our assay in four kidney-transplant patients with both stimulator cell types from the corresponding donor to compare the amount of detectable alloantigen-reactive T cells. Analysis of the HLA-ABC and -DR expression on splenocytes showed a high expression of both molecules. After treatment with IFN $\gamma$ and TNF $\alpha$ the expression slightly decreased (Fig. 4A, upper row), which might be due to a decreased viability (not shown). In comparison, the basal expression of HLA-DR on the TEC of the same donor was very low and inducible by IFN $\gamma$ and TNF $\alpha$ treatment, but stayed lower in comparison to splenocytes (Fig. 4A-C). To compare the stimulatory capacity of the TEC, as a novel source of stimulator cells directly from the kidney allograft, to splenocytes from the same donor as the most commonly used source, we analysed the respective allograft-reactive T cell responses. We lysed a fraction of the TEC and splenocytes and incubated them together with the respective intact cells to facilitate presentation by antigen presenting cells and to mimic ischemic cell death that can occur during transplantation. The analysis was performed in four patients at different time points pre- and post-transplantation, making a total of 15 samples. We detected on average 8 times higher median frequencies of activated $\mathrm{CD} 4^{+} \mathrm{T}$ cells in samples stimulated with donor TEC compared to donor-derived splenocytes (Fig. 4D; $P=0.0001, n=15$ ). These data thus show that TEC can elicit a stronger donor-specific $\mathrm{CD} 4^{+} \mathrm{T}$ cell response than splenic antigen presenting cells can.

Characteristics of patients in follow up-study. It has been shown before that measurement of pre-transplant donor-reactive $\mathrm{T}$ cells can predict the post-transplantation kidney-function and $\mathrm{AR}^{13,23-26}$. To confirm the capacity of our method to quantify donor-reactive T cells and predict the post-transplant clinical course we collected PBMCs of fourteen patients before transplantation. Thereafter, the patients were clinically followed up for 6 months after transplantation. Two patients developed biopsy-proven early acute rejection (AR 


\begin{tabular}{|c|c|c|c|}
\hline \multicolumn{2}{|l|}{ Parameter } & \multirow{2}{*}{$\begin{array}{l}\begin{array}{l}\text { Control patients (No DGF, no AR) } \\
n=10\end{array} \\
64.5(31-77)\end{array}$} & \multirow{2}{*}{$\begin{array}{l}\text { AR-patients } \\
\boldsymbol{n}=\mathbf{2}\end{array}$} \\
\hline \multirow{9}{*}{ Recipient } & Age year, median (range) & & \\
\hline & Sex male/female & $8 / 2$ & $2 / 0$ \\
\hline & Underlying renal disease & $\begin{array}{l}\text { Glomerulonnephritis }(n=3) \text {, diabetic nephropathy } \\
(n=1) \text {, hypertensive nephropathy }(n=1) \text {, chronic } \\
\text { pyelonephritis }(n=1) \text {, interstitial nephritis }(n=1) \text {, CNI- } \\
\text { toxicity after previous lung-tx }(n=1) \text { and unknown }(n=2)\end{array}$ & $\begin{array}{l}\text { Autosomal dominant polycistic } \\
\text { kidney disease }(n=1) \\
\text { glomerulonephritis }(n=1)\end{array}$ \\
\hline & Previous kidney transplant & $10 \%$ & $50 \%$ \\
\hline & Previous transplant other than kidney & $10 \%$ & $0 \%$ \\
\hline & $\begin{array}{l}\text { Time on dialysis before } \mathrm{Tx} \\
\text { years, median (range) }\end{array}$ & $5(3-11)$ & $12(12)$ \\
\hline & Current PRA & $0 \%$ & $0 \%$ \\
\hline & Induction immunosuppression & Basiliximab & Basiliximab \\
\hline & Maintenance immunosuppression & $\begin{array}{l}\text { Tacrolimus, mycophenolat-mofetil, methylprednisolone } \\
(n=9) \\
\text { Cyclosporine, everolimus, methylprednisolone }(n=1)\end{array}$ & $\begin{array}{l}\text { Tacrolimus, mycophenolate- } \\
\text { mofetil, methylprednisolone }\end{array}$ \\
\hline \multirow{2}{*}{ Donor-recipient } & $\begin{array}{l}\text { HLA-mismatches broad } \\
\text { median (range) }\end{array}$ & $4(0-6)$ & $5(4-6)$ \\
\hline & $\begin{array}{l}\text { Cold ischemia time } \\
\text { hours, median (range) }\end{array}$ & $7(4-17)$ & $12(9-15)$ \\
\hline \multirow{2}{*}{ Donor } & Age year, median (range) & $59(23-74)$ & $75(74-76)$ \\
\hline & Sex male/female & $4 / 6$ & $1 / 1$ \\
\hline
\end{tabular}

Table 1. Characteristics of control and acute rejection (AR) patients in follow-up TreaT-assay.

group). Ten patients showed a stable graft function and no signs for delayed graft function, AR or other relevant post-transplant complications (control group). One patient showed multiple surgical and infectious complications post-transplantation. Another patient showed a good transplant function initially but a deterioration of kidney function two weeks after transplantation. Both patients had single transplant-biopsies with inconclusive findings regarding immunological complications, so they were not included into the analysis. The demographic and clinical characteristics of the 10 control patients and the $2 \mathrm{AR}$ patients are presented in Table 1. Briefly, eight control patients were male and two female. Their age at transplantation was 64.5 (32-77) years (median, range). The immunosuppression regimen of nine control patients consisted of tacrolimus, mycophenolat-mofetil and methylprednisolone, one patient received a regimen with everolimus, cyclosporine and methylprednisolone. Two of the twelve monitored patients developed a biopsy-proven cellular AR at early stage after transplantation, confirmed via biopsy. They were both male and their median age at transplantation 73.5 (74-76) years (median, range). Their therapeutic regimen after transplantation consisted of a maintenance immunosuppression with tacrolimus, mycophenolate-mofetil, and methylprednisolone.

Pre-transplant alloreactive T cells measured with the TreaT-assay correspond with the post-transplant outcome. To determine phenotypical and functional subsets of alloreactive $\mathrm{T}$ cells we applied multi-color flow cytometry (Fig. 5A). The pre-transplant numbers of alloreactive T cells correlated negatively with the eGFR (CKD-EPI) 6 months post-transplantation. In detail, this could be seen for alloreactive $\mathrm{CD}^{+}(r=-0.5566, P=0.0387, n=14)$ as well as $\operatorname{CD}^{+}(r=-0.6397, P=0.0138, n=14)$ T cells (Fig. 5B,C).

To confirm that the established assay can be used to predict early AR episodes, twelve transplant patients were grouped into a control group without immunological complications $(n=10)$ and an AR group with biopsy proven rejection $(n=2)$ and analysed in a pilot study. The frequencies of alloreactive T cells were measured in samples obtained immediately before transplantation. The number of alloreactive $\mathrm{CD} 4^{+}$and $\mathrm{CD} 8^{+} \mathrm{T}$ cells before transplantation was higher in the two AR patients compared to controls. Comparing these results by a Mann-Whitney test resulted in significant differences ( $P=0.0152$ in both subsets), but as applying statistical tests in experiments with low sample numbers is controversial we refrained from depicting the $P$-value (Fig. 5B,C). The number of allograft-reactive $\mathrm{CD} 154^{+}$and/or $\mathrm{CD} 137^{+} \mathrm{CD} 161^{+} \mathrm{CD} 4^{+} \mathrm{T}$ cells and of $\mathrm{CD} 137^{+}$granzyme $\mathrm{B}$ producing $\mathrm{CD}^{+} \mathrm{T}$ cells could clearly distinguish between patients that developed an early AR and patients with an uncomplicated course after transplantation (Fig. 5D). CD161 is a marker for TH17 cells ${ }^{27}$, which are important players in the $\mathrm{T}$ cell reaction towards the allograft ${ }^{28}$. Granzyme B has been introduced as a marker for AR after kidney transplantation before ${ }^{29}$.

\section{Discussion}

$\mathrm{T}$ cell-mediated rejection is a common threat after kidney transplantation ${ }^{1}$. Donor-reactive $\mathrm{T}$ cells suggested to be involved in pathogenesis of AR can be generated prior to transplantation, for example during pregnancies, blood transfusions, previous transplantations or as cross-reactive T cells during infections ${ }^{30}$. They are of special interest, since they may allow the prediction of the immediate post-transplant clinical course ${ }^{8}$. CD $4^{+}$and CD8 ${ }^{+}$ memory $\mathrm{T}$ cells can act without secondary lymphoid organs ${ }^{31}$, which enables monitoring their reactivity ex vivo in a short-term stimulation approach ${ }^{32}$. Previously, we and others could show that the number of pre-transplant donor-reactive IFN $\gamma$-producing cells measured by ELISPOT correlates with post-transplant glomerular filtration rate ${ }^{23-25}$ and predicts early $\mathrm{AR}^{13,26,33,34}$. However, stimulator cells applied in these assays pose several limitations. 
a
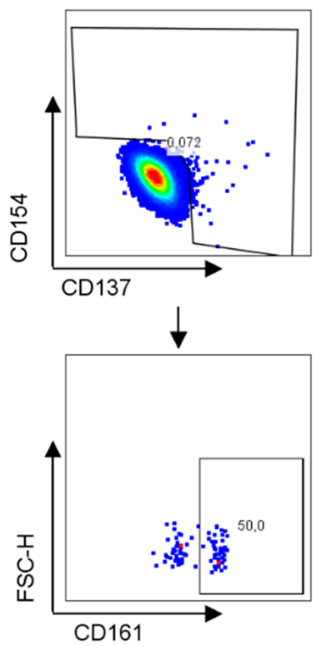

b

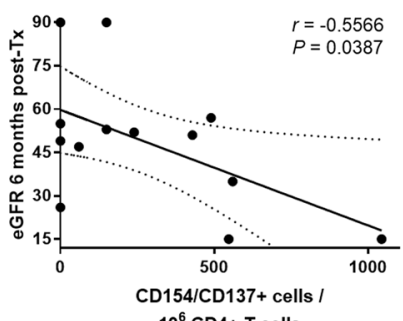

d

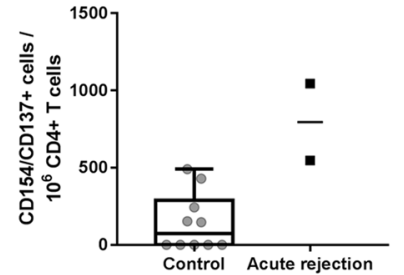

f

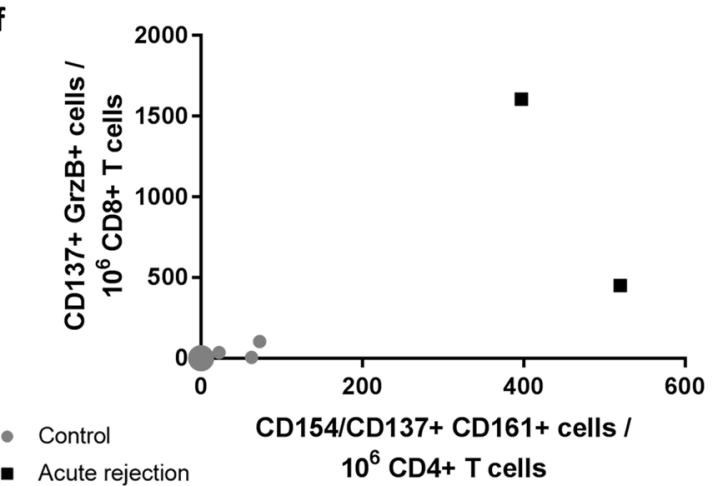

CD8+ T-cells

C

e

00

Acute rejection
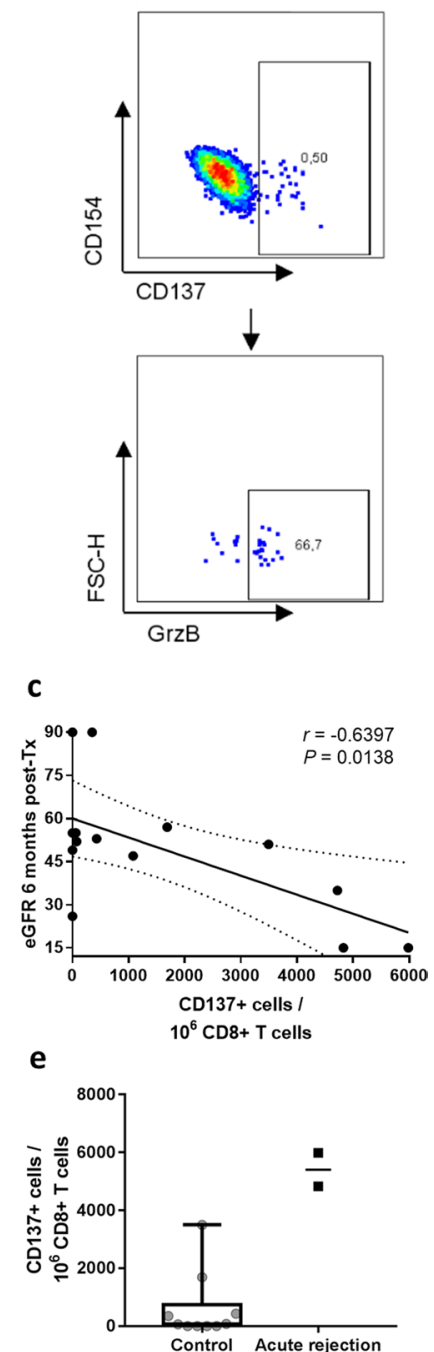

Figure 5. Pre-transplant alloreactive T cells measured with the TreaT-assay correspond with the posttransplant outcome. (a) Representative gating strategy to identify allograft-reactive T cell subsets. (b,c) Analysis of donor-reactive T cells collected before transplantation ( $n=14$ patients). Recipient's PBMC were stimulated with the corresponding urine-derived donor TEC for $16 \mathrm{~h}$. Before incubation, the TEC were treated with $20 \mathrm{ng} /$ $\mathrm{ml}$ IFN $\gamma$ and $10 \mathrm{ng} / \mathrm{ml}$ TNF $\alpha$ for $24 \mathrm{~h}$ and a fraction of the TEC lysed to facilitate presentation by antigen presenting cells. After incubation, the PBMC were analyzed by flow cytometry for frequencies of alloreactive T cells. Correlation with the eGFR (CKD-EPI) at 6 months post-transplantation with pre-transplant alloreactive $\mathrm{CD}^{+}(\mathbf{b})$ and $\mathrm{CD}^{+}(\mathbf{c}) \mathrm{T}$ cells was calculated with Pearson's correlation coefficient. Dotted lines show $95 \%$ confidence bands. (d-e) Two patients of the previously described cohort developed biopsy-proven early acute rejection $(\mathrm{AR})$ in clinical follow-up, and the frequencies of their pre-transplant alloreactive $\mathrm{CD} 4^{+}(\mathbf{d})$ and $\mathrm{CD}^{+}$(e) $\mathrm{T}$ cells were compared to ten patients without immunological complications in the first six months after transplantation (control group). Whiskers show minimal and maximal values. (f) Further characterization 
of alloreactive $\mathrm{CD} 4^{+} \mathrm{T}$ cells by the expression of TH17 marker CD161 and of alloreactive CD8 ${ }^{+} \mathrm{T}$ cells by production of Granzyme B. Gray dots show control patients $(n=10)$, the large gray dot conjoins 7 individual patient data. Black squares show patients with biopsy-proven early AR $(n=2)$.

They are either of restricted availability (splenocytes) or lack sufficient matching (HLA-bank cells). Furthermore, functional and phenotypic analysis of alloreactive cells with ELISPOT applied in previous studies is very limited ${ }^{3}$. Here, we present the Transplant reactive T cells (TreaT)-Assay, a novel multi-parameter flow cytometry-based diagnostic tool using an easily accessible and renewable urine-derived donor-specific source of stimulator cells for monitoring allograft-specific T cells. Compared to the currently used sources our model has the advantages of high quantity, availability, and quality.

The cultivation process is easy to perform. The outgrowth of cells from the urine worked for all patients included in our study. As we could show, the majority of cells in the cultures are TEC. Since the urine was collected from a pigtail catheter, the allograft origin of TEC can be ensured. Therefore, this method offers a non-invasive way to procure kidney allograft cells.

Regarding the quality, urinary cells have been shown earlier to be fully functional renal tubular cells ${ }^{35}$. Most important in our setting is their stimulatory capacity. We could show that urine-derived TEC, like TEC from other sources $^{21,36}$, up-regulate both HLA-ABC and -DR molecules in a pro-inflammatory environment. These cells can therefore act as atypical antigen presenting cells and activate memory $\mathrm{T}$ cells ${ }^{37,38}$. The specificity of alloreactive $\mathrm{T}$ cells and the influence of pro-inflammatory conditions on the stimulatory capacity of TEC is displayed by the differing reactivity of $\mathrm{CD} 4^{+}$and $\mathrm{CD} 8^{+} \mathrm{T}$ cells. Homeostatic HLA-ABC expression was sufficient to trigger $\mathrm{a} \mathrm{CD}^{+} \mathrm{T}$ cell response, while CD4 ${ }^{+} \mathrm{T}$ cells only reacted on inflammatory treated TEC with upregulated HLA-DR molecules. Further, comparing autologous with allogenic stimulation, we could demonstrate that the activation of T cells followed by TEC stimulation was due to allogenic capacity of TEC and not due to unspecific cytokine pre-treatment of TEC. Thus, T cells of healthy volunteers show little to no reaction towards autologous TEC, while allogenic TEC could elicit a measurable reactivity. Taken together, these experiments show that TEC have the ability to induce a specific $T$ cell alloreaction without provoking significant unspecific reactivity.

Knowing that we can specifically monitor TEC-induced donor-reactive T cells, we assessed the sensitivity of our assay in comparison to splenocytes, currently the most commonly used stimulator source. Previously, some authors stated the existence of tissue-specific alloreactivity by HLA-molecules presenting kidney cell specific peptides ${ }^{39}$. Accordingly, splenocytes would only monitor a fraction of the alloreactive T cells as their HLA-molecules do not bind the peptides present in the kidney-allograft. The existence of tissue-specific T cells in the kidney-transplantation setting was already shown more than two decades ago by demonstrating that some clones of graft-infiltrating T cells lyse TEC, but not splenocytes isolated from the corresponding donor ${ }^{39-45}$. In line with these results, we observed a significantly lower reactivity upon stimulation with donor-splenocytes as compared to the donor-derived TEC, despite a higher expression of HLA-molecules on the splenocytes. This underscores the superiority of our TEC-based alloreactivity-assay and suggests that it may reflect donor- and tissue-specific reactivity as well as the intragraft situation more accurately than currently used sources for stimulator cells.

To prove the clinical utility of the established assay, we performed a proof-of-principle study on the correlation of pre-transplant alloreactive T cells measured by the TreaT-assay and the post-transplant GFR as well as early AR. As it has been shown also for the IFN $\gamma$-ELISPOT-assay ${ }^{23-25}$, pre-transplant alloreactive CD $4^{+}$and $\mathrm{CD}^{+} \mathrm{T}$ cells inversely correlated with the eGFR at 6 months post transplantation. The prediction of AR with IFN $\gamma$-ELISPOT showed differing results in clinical trials ${ }^{13,23-26,33,34}$. Comparing patients with very early AR to patients with a stable graft function in our assay, AR patients showed a higher number of alloreactive CD4 ${ }^{+}$and $\mathrm{CD} 8^{+} \mathrm{T}$ cells and a clear distinction between these two groups can be drawn when the numbers of alloreactive $\mathrm{CD} 161^{+} \mathrm{CD} 4^{+} \mathrm{T}$ cells and of granzyme B producing $\mathrm{CD} 8^{+} \mathrm{T}$ cells are compared. $\mathrm{CD} 161$ is a marker restricted to memory phenotype and a hallmark of TH17 cells and interleukin-17 production ${ }^{27,46}$. Our data are in line with the results by numerous authors demonstrating the involvement of TH17 cells in alloreaction ${ }^{28}$. In addition, Kim et al. demonstrated very recently a significant increase of $\mathrm{CD} 161^{+} \mathrm{CD} 4^{+} \mathrm{T}$ cells in patients with antibody-mediated rejection confirming thereby our data on the role of this cell subset in the alloreactivity ${ }^{47}$. The involvement of granzyme B in AR has also been intensely studied and demonstrated before ${ }^{29}$. Taken together, the detection of $\mathrm{CD} 161^{+} \mathrm{CD}^{+}$and granzyme $\mathrm{B}$ in our patients with early AR reported to be relevant in other ex vivo and in vivo studies provides evidence for the clinical relevance of the data collected.

Our study has some limitations. Similar to other studies performed on peripheral blood cells, our ex vivo analyses do not necessarily reflect the intragraft situation. Therefore, in future studies a comparison with the biopsy findings in follow-up would be needed. However, this is challenging due to ethical reasons. Furthermore, the numbers of some alloreactive T cell subsets were relatively low. Detection of very low numbers of antigen-specific $\mathrm{T}$ cells in kidney transplant patients has been demonstrated before for virus-specific and vaccine-specific $\mathrm{T}$ cells $^{48-50}$. Quality controls for data acquisition and analyses including subtraction of unspecific background and adequate fluorescence-minus-one controls as applied in our studies enable however reliable detection of these cells. On the other hand, analysis of a higher cell number would facilitate identification and in-depth characterization of alloreactive T cells, especially with regard to cytokines or quantification of rare subpopulations. Therefore, drawing higher amounts of blood (e.g. $20 \mathrm{~mL}$ ) will be advantageous and can be drawn unproblematicly in most cases. Moreover, the number of patients analysed in our proof-of-concept pilot study is insufficient to draw final conclusions on the applicability and prognostic power of our assay and further prospective studies will be required to confirm and extend our data. Additionally, so far we did not perform a direct comparison with similar assays using IFN $\gamma$-ELISPOT with donor-splenocytes or HLA-bank cells. Nonetheless, our results are 
in line with similar assays measuring allograft-reactive T cells in comparable patient cohorts. Further, the time needed for the first results is a critical point in a clinical setting. In order to achieve sufficient numbers of TEC, up to two weeks are necessary, depending on the amount of urine and the sediment quality. However, a combination of the aforementioned sources, such as splenocytes, could bridge this diagnostic window. Another option is down scaling of TEC numbers for stimulation, which is also envisioned for future studies.

Taken together, the TreaT-assay offers a donor-specific measurement of allograft reactive T cells. Compared to previous assays it has the advantages of an unlimited availability and a superior performance. In a pilot study, we were able to obtain encouraging data on the applicability of our assay in patients with early AR and on the prediction of post-transplant GFR. Furthermore, our approach allows deep personalized insights into the biology of alloreactive immune cells and their interaction with donor TEC. Therefore, it might help to guide personalized therapy in the future of kidney transplantation.

\section{Data availability}

The raw data supporting the conclusions of this manuscript will be made available by the authors, without undue reservation, to any qualified researcher.

Received: 16 August 2019; Accepted: 19 November 2019;

Published online: 13 December 2019

\section{References}

1. Randhawa, P. T-cell-mediated rejection of the kidney in the era of donor-specific antibodies. Curr. Opin. Organ Transplant. 20, 325-332 (2015).

2. Pratschke, J. et al. Immunological risk assessment: The key to individualized immunosuppression after kidney transplantation. Transplant. Rev. 30, 77-84 (2016).

3. Babel, N., Reinke, P. \& Volk, H.-D. Lymphocyte markers and prediction of long-term renal allograft acceptance. Curr. Opin. Nephrol. Hypertens. 18, 489-494 (2009).

4. Cravedi, P. \& Heeger, P. S. Immunologic monitoring in transplantation revisited. Curr. Opin. Organ Transplant. 17, 26-32 (2012).

5. Angeletti, A. \& Cravedi, P. Looking into the Graft without a Biopsy: Biomarkers of Acute Rejection in Renal Transplantation. in. Contributions to nephrology 190, 181-193 (2017).

6. Peeters, L. E. J., Andrews, L. M., Hesselink, D. A., de Winter, B. C. M. \& van Gelder, T. Personalized immunosuppression in elderly renal transplant recipients. Pharmacol. Res. 130, 303-307 (2018).

7. Bestard, O. et al. Prospective assessment of antidonor cellular alloreactivity is a tool for guidance of immunosuppression in kidney transplantation. Kidney Int. 84, 1226-36 (2013).

8. Espinosa, J. R., Samy, K. P. \& Kirk, A. D. Memory T cells in organ transplantation: progress and challenges. Nat. Rev. Nephrol. 12, 339-47 (2016).

9. Morris, H. et al. Tracking donor-reactive T cells: Evidence for clonal deletion in tolerant kidney transplant patients. Sci. Transl. Med. 7, 272ra10 (2015).

10. Andree, H. et al. Identification of dialysis patients with panel-reactive memory T cells before kidney transplantation using an allogeneic cell bank. J. Am. Soc. Nephrol. 17, 573-80 (2006).

11. Cravedi, P., van der Touw, W. \& Heeger, P. S. Complement regulation of T-cell alloimmunity. Semin. Nephrol. 33, 565-74 (2013).

12. Heeger, P. S. et al. Pretransplant frequency of donor-specific, IFN-gamma-producing lymphocytes is a manifestation of immunologic memory and correlates with the risk of posttransplant rejection episodes. J. Immunol. 163, 2267-75 (1999).

13. Gandolfini, I. et al. Impact of preformed T-cell alloreactivity by means of donor-specific and panel of reactive T cells (PRT) ELISPOT in kidney transplantation. PLoS One 13, e0200696 (2018).

14. Robertson, H., Wheeler, J., Kirby, J. A. \& Morley, A. R. Renal allograft rejection-in situ demonstration of cytotoxic intratubular cells. Transplantation 61, 1546-9 (1996).

15. Zhou, T. et al. Generation of human induced pluripotent stem cells from urine samples. Nat. Protoc. 7, 2080-9 (2012).

16. Cossarizza, A. et al. Guidelines for the use of flow cytometry and cell sorting in immunological studies. Eur. J. Immunol. 47, 1584-1797 (2017).

17. Baer, P. C., Nockher, Wa, Haase, W. \& Scherberich, J. E. Isolation of proximal and distal tubule cells from human kidney by immunomagnetic separation. Technical note. Kidney Int. 52, 1321-31 (1997).

18. Trzpis, M. et al. Expression of EpCAM is up-regulated during regeneration of renal epithelia. J. Pathol. 216, 201-8 (2008).

19. van Kooten, C., Lam, S. \& Daha, M. R. Isolation. culture, characterization and use of human renal tubular epithelial cells. J. Nephrol. 14, 204-210 (2001).

20. Demmers, M. W. H. J. et al. Differential effects of activated human renal epithelial cells on T-cell migration. PLoS One 8, e64916 (2013).

21. Wilson, J. L., Proud, G., Forsythe, J. L., Taylor, R. M. \& Kirby, J. A. Renal allograft rejection. Tubular epithelial cells present alloantigen in the presence of costimulatory CD28 antibody. Transplantation 59, 91-7 (1995).

22. Schoenbrunn, A. et al. A converse 4-1BB and CD40 ligand expression pattern delineates activated regulatory T cells (Treg) and conventional T cells enabling direct isolation of alloantigen-reactive natural Foxp3+ Treg. J. Immunol. 189, 5985-94 (2012).

23. Nickel, P. et al. Enzyme-linked immunosorbent spot assay for donor-reactive interferon-gamma-producing cells identifies T-cell presensitization and correlates with graft function at 6 and 12 months in renal-transplant recipients. Transplantation 78, 1640-1646 (2004).

24. Näther, B. J. et al. Modified ELISPOT technique - Highly significant inverse correlation of post-Tx donor-reactive IFN $\gamma$-producing cell frequencies with 6 and 12 months graft function in kidney transplant recipients. Transpl. Immunol. 16, 232-237 (2006).

25. Hricik, D. E. et al. Interferon Gamma ELISPOT Testing as a Risk-Stratifying Biomarker for Kidney Transplant Injury: Results From the CTOT-01 Multicenter Study. Am. J. Transplant. 15, 3166-3173 (2015).

26. Poggio, E. D. et al. Pretransplant cellular alloimmunity as assessed by a panel of reactive $\mathrm{T}$ cells assay correlates with acute renal graft rejection. Transplantation 83, 847-852 (2007).

27. Cosmi, L. et al. Human interleukin 17-producing cells originate from a CD161+CD4+ T cell precursor. J. Exp. Med. 205, 1903-1916 (2008).

28. Liu, Z., Fan, H. \& Jiang, S. CD4(+) T-cell subsets in transplantation. Immunol. Rev. 252, 183-91 (2013).

29. Heng, B. et al. A Meta-analysis of the Significance of Granzyme B and Perforin in Noninvasive Diagnosis of Acute Rejection After Kidney Transplantation. Transplantation 99, 1477-1486 (2015).

30. D’Orsogna, L., van den Heuvel, H., van Kooten, C., Heidt, S. \& Claas, F. H. J. Infectious pathogens may trigger specific allo-HLA reactivity via multiple mechanisms. Immunogenetics 69, 631-641 (2017). 
31. Ng, Y.-H. \& Chalasani, G. Role of secondary lymphoid tissues in primary and memory T-cell responses to a transplanted organ. Transplant. Rev. (Orlando). 24, 32-41 (2010).

32. Matesic, D., Lehmann, P. V. \& Heeger, P. S. High-resolution characterization of cytokine-producing alloreactivity in naive and allograft-primed mice. Transplantation 65, 906-14 (1998).

33. Koscielska-Kasprzak, K. et al. Pretransplantation Cellular Alloreactivity Is Predictive of Acute Graft Rejection and 1-Year Graft Function in Kidney Transplant Recipients. Transplant. Proc. 41, 3006-3008 (2009).

34. Kim, S. H. et al. Pretransplant Donor-Specific Interferon- $\gamma$ ELISPOT Assay Predicts Acute Rejection Episodes in Renal Transplant Recipients. Transplant. Proc. 39, 3057-3060 (2007).

35. Inoue, C. N. et al. Reconstruction of tubular structures in three-dimensional collagen gel culture using proximal tubular epithelial cells voided in human urine. In Vitro Cell. Dev. Biol. Anim. 39, 364-7 (2003).

36. Nguan, C. Y. C. \& Du, C. Renal tubular epithelial cells as immunoregulatory cells in renal allograft rejection. Transplant. Rev. 23, $129-138(2009)$

37. Kambayashi, T. \& Laufer, T. M. Atypical MHC class II-expressing antigen-presenting cells: can anything replace a dendritic cell? Nat. Rev. Immunol. 14, 719-730 (2014).

38. Shiao, S. L., McNiff, J. M. \& Pober, J. S. Memory T cells and their costimulators in human allograft injury. J. Immunol. 175, 4886-96 (2005).

39. D’Orsogna, L. J., Roelen, D. L., Doxiadis, I. I. N. \& Claas, F. H. J. TCR cross-reactivity and allorecognition: new insights into the immunogenetics of allorecognition. Immunogenetics 64, 77-85 (2012).

40. Yard, B. A. et al. Recognition of a tissue-specific polymorphism by graft infiltrating T-cell clones isolated from a renal allograft with acute rejection. Nephrol. Dial. Transplant. 9, 805-810 (1994).

41. Poindexter, N. J. et al. Cytolytic T lymphocytes from human renal allograft biopsies are tissue specific. Hum. Immunol. 44, 43-49 (1995).

42. Mohanakumar, T. et al. Tissue-specific HLA class I restricted CTL are a significant subpopulation of graft-infiltrating lymphocytes during rejection. Transplant. Proc. 29, 87-88 (1997).

43. Deckers, J. G., Boonstra, J. G., Van der Kooij, S. W., Daha, M. R. \& Van der Woude, F. J. Tissue-specific characteristics of cytotoxic graft-infiltrating T cells during renal allograft rejection. Transplantation 64, 178-81 (1997).

44. Deckers, J. G., Daha, M. R., Van der Kooij, S. W. \& Van der Woude, F. J. Epithelial- and endothelial-cell specificity of renal graft infiltrating T cells. Clin. Transplant. 12, 285-91 (1998).

45. Yard, B. A. et al. Analysis of T cell lines from rejecting renal allografts. Kidney Int. Suppl. 39, S133-8 (1993).

46. Fergusson, J. R., Fleming, V. M. \& Klenerman, P. CD161-expressing human T. cells. Front. Immunol. 2(2), 36 (2011)

47. Kim, K. W. et al. Clinical significance of CD161+CD4+ T cells in the development of chronic antibody-mediated rejection in kidney transplant recipients. PLoS One 13, e0200631 (2018).

48. Mueller, K. et al. BK-VP3 as a new target of cellular immunity in BK virus infection. Transplantation 91, 100-7 (2011).

49. Weist, B. J. D. et al. A revised strategy for monitoring BKV-specific cellular immunity in kidney transplant patients. Kidney Int. 88, 1293-1303 (2015).

50. Rambal, V. et al. Differential influenza H1N1-specific humoral and cellular response kinetics in kidney transplant patients. Med. Microbiol. Immunol. 203, 35-45 (2014).

\section{Acknowledgements}

We are grateful to Anett Sefrin, Hanna Zobel, Silvia Fischer, Astrid Wilke, and Gabriele Oberüber for their support with patient recruitment. We express our deep gratitude to all patients and healthy donors that participated in the study. We thank the European Society for Organ Transplantation (ESOT), the German Transplantation Society (DTG) and the American Society of Transplantation (AST) for the opportunity to present our method and preliminary results at their congresses. The study was supported by BMBF grant e:Med consortium, projects e:KID and MicModeI2T. We acknowledge support from the German Research Foundation (DFG) and the Open Access Publication Funds of Charité - Universitätsmedizin Berlin.

\section{Author contributions}

C.T. collected patient samples, designed and performed experiments, analyzed and interpreted data, and wrote the paper. B.W. designed and performed experiments and analyzed and interpreted data. A.M. collected patient samples and performed experiments. T.R. performed experiments and edited the manuscript. U.S. analyzed data. K.R. established the protocol for the UC cultivation. P.W. collected patient samples and performed experiments. M.S. processed donor spleens. M.C. and P.N. took care of the patients in the transplantation ambulance, collected clinical data and patient samples. N.L. performed and analyzed experiments. A.K., M.S.-H., T.W. and P.R. supervised and helped design the study. N.B. took clinical care of the kidney transplant patients, designed the study and the experiments, interpreted data and wrote the paper. All authors approved the final version of the manuscript.

\section{Competing interests}

C.T., B.W., P.R. and N.B. applied for a European patent (EP3203237A1). The other authors declare no potential conflict of interests.

\section{Additional information}

Supplementary information is available for this paper at https://doi.org/10.1038/s41598-019-55442-x.

Correspondence and requests for materials should be addressed to N.B.

Reprints and permissions information is available at www.nature.com/reprints.

Publisher's note Springer Nature remains neutral with regard to jurisdictional claims in published maps and institutional affiliations. 
(c) (i) Open Access This article is licensed under a Creative Commons Attribution 4.0 International License, which permits use, sharing, adaptation, distribution and reproduction in any medium or format, as long as you give appropriate credit to the original author(s) and the source, provide a link to the Creative Commons license, and indicate if changes were made. The images or other third party material in this article are included in the article's Creative Commons license, unless indicated otherwise in a credit line to the material. If material is not included in the article's Creative Commons license and your intended use is not permitted by statutory regulation or exceeds the permitted use, you will need to obtain permission directly from the copyright holder. To view a copy of this license, visit http://creativecommons.org/licenses/by/4.0/.

(C) The Author(s) 2019 